\title{
Enterochromaffin Cells and Mast Cells in Acute Appendicitis
}

\author{
Bhavya P. Mohan ${ }^{1} \quad$ K.P. Aravindan² \\ ${ }^{1}$ Department of Pathology, Government Medical College, \\ Thrissur, Kerala, India \\ 2ICMR Emeritus Scientist, Government Medical College, \\ Calicut, Kerala, India
}

J Lab Physicians:2020;12:141-146

\begin{abstract}
Address for correspondence Bhavya P. Mohan, MD, Assistant Professor, Department of Pathology, Government Medical College, Thrissur 680596, Kerala, India (e-mail: bhavyasharath80@gmail.com).
\end{abstract}

\begin{abstract}
Keywords

- serotonin

- acute appendicitis

- mast cells

- enterochromaffin cells

- allergy

Background and Objective Serotonin levels are increased in acute appendicitis. We investigated the possible source of this increase. The aim of this study was to compare the distribution and density of epithelial and nonepithelial enterochromaffin (EC) cells as well as numbers of degranulated and nondegranulated mast cells in different layers of normal appendices and acute appendicitis.

Methods Sections from 15 cases of acute appendicitis and 10 cases where the appendix was morphologically normal were stained with Hematoxylin \& Eosin, Toluidine blue, and immunohistochemically for chromogranin and CD-117. EC cells stained by chromogranin were counted per crypt and extraepithelial EC cells counted and expressed as cells per unit area $\left(\mathrm{mm}^{2}\right)$. Mast cells stained by Toluidine blue and CD-117 were counted in lamina propria, submucosa, and muscle layers. The difference between Toluidine blue and CD117 stained mast cells was taken to be an estimate of degranulated cells. The cell counts were expressed per unit area $\left(\mathrm{mm}^{2}\right)$ as well as per cross-sectional area of the appendix.

Results There was no statistically significant difference in epithelial and extraepithelial EC cells between acute appendicitis and normal appendix. Estimated mast cell degranulation as indicated by mast cell counts per cross-sectional area is greatly increased in acute appendicitis when compared with normal.

Conclusion Degranulated mast cells rather than EC cells may be the main source of raised serotonin in acute appendicitis.
\end{abstract}

\section{Introduction}

The prominent theories regarding the etiopathogenesis of acute appendicitis are as varied as mechanical obstruction to allergy and free radical injury to ischemia. Enterochromaffin (EC) cells are found in mucosal layer of entire intestinal system but are most prominent in distal appendix and comprise the major cell type in intestinal endocrine system. Serotonin is the main secretory product of EC cells. ${ }^{1}$ Serotonin levels have been demonstrated to be high in the serum of patients with acute appendicitis and EC cells (both epithelial and nonepithelial) are its suggested source. ${ }^{2}$ This study compares patterns obtained by immunohistochemistry between normal appendices and acute appendicitis to find out the source of the raised serotonin in acute appendicitis. Allergic etiology has been proposed as a cause for acute appendicitis because of high degree of eosinophil infiltration in the tissue and evidence of eosinophil degranulation., ${ }^{3,4}$ This study was designed to probe whether degranulated mast cells rather than EC cells, could be a putative source of raised serotonin in acute appendicitis, supporting its allergic origin.

\section{Materials and Methods}

\section{Subjects}

Sections from 25 specimens of appendix were studied. Cases were 15 specimens of histologically proven acute appendicitis and controls were 10 specimens of histologically normal 
appendix with absence of exudates, mucosal ulceration, or mucosal neutrophils. Acute appendicitis was defined by the presence of neutrophils in the muscle layer.

\section{Procedure}

All specimens were fixed in $10 \%$ formalin. Three cross sections were taken from each specimen representing the base, middle, and the tip of the appendix. They were routinely processed, paraffin embedded, and stained with Hematoxylin and Eosin (H\&E), Toluidine blue, and immunohistochemically for Chromogranin and CD-117 (heat-induced epitope retrieval [HIER]). Mean counts of various cells between acute appendicitis and normal appendix were performed.

\section{Toluidine Blue Staining}

Formalin fixed paraffin-embedded tissue sections of $4 \mu \mathrm{m}$ were deparaffinized and hydrated. Sections were then treated with Toluidine blue working solution (prepared from Toluidine blue stock solution) for 1 minute, rinsed in distilled water and dehydrated quickly through $95 \%$ and absolute alcohols, cleared in xylene and mounted. Mast cell granules were stained violet.

Toluidine blue stock solution: Toluidine blue 0-1.0 g and 70\% alcohol-100.0 mL.

Working solution: Toluidine blue, stock-5.0 mL and $1 \%$ sodium chloride $-45.0 \mathrm{~mL}$.

\section{Immunohistochemistry}

Formalin fixed paraffin-embedded tissue sections of 3 to $4 \mu \mathrm{m}$ were taken on poly-l-lysine-coated slides. The slides were fixed overnight in an incubator at $60^{\circ} \mathrm{C}$, dewaxed and hydrated in running tap water followed by distilled water for 5 minutes. Epitope retrieval was done with Tris ethylene-diamine-tetraacetic acid borate buffer by heat method (HIER) in pressure cooker for 10 minutes followed by cooling to room temperature and washing with distilled water. Slides were then treated with endogenous peroxidase block for 20 minutes. Further, slides were kept in tris buffered saline wash buffer for 5 minutes. The sections were then blotted after treatment with power block for 10 minutes. Primary mouse antihuman antibodies against chromogranin (BioGenex; Clone LK2H10) and CD117 (BioGenex; Clone T595) were applied for an hour, and then washed with wash buffer, three times for 5 minutes. Superenhancer was added for 25 minutes. Secondary antibody was applied for 25 minutes and then washed with wash buffer, three times for 2 minutes. Diaminobenzidine chromogen was applied for 5 minutes, washed with wash buffer for 5 minutes, and rinsed in distilled water for 5 minutes to stop chromogen reaction. Sections were counterstained with Harris hematoxylin for 2 minutes, then blued for 5 minutes, dehydrated, cleared, and mounted with dibutylphthalate polystyrene xylene (DPX).

\section{Counting}

EC cells stained by chromogranin were counted per crypt (epithelial EC cells) and extraepithelial EC cells counted and expressed as cells per unit area $\left(\mathrm{mm}^{2}\right)$. Eosinophils were counted in the muscle layer (H\&E), mast cells stained by Toluidine blue and CD-117 counted in lamina propria, submucosa, and muscle layers. The difference between Toluidine blue and CD117 stained mast cells was taken to be an estimate of degranulated cells. The mast cell counts were expressed per unit area $\left(\mathrm{mm}^{2}\right)$ as well as per whole area of the lamina propria, submucosa, and muscle layer of the appendix. All cell counts were obtained using the high-power objective.

The diameter of the appendix was measured with an eyepiece micrometer and the center point determined. From this center, radius of the circles representing the inner mucosal lining (ra), edge of the lamina propria ( $\mathrm{rb}$ ), outer end of the submucosa ( $\mathrm{rc}$ ), and the outer edge of the muscularis propria (rd) were measured. From these, the approximate areas represented by the lamina propria, submucosa, and the muscle layer can be calculated. For example, the muscle area would be $\left(\pi \mathrm{r}^{2}\right)-\left(\pi \mathrm{rc}^{2}\right)$.

The cell counting in each layer was started from a point marked on the section, continued in a circular fashion along the particular layer, and stopped when the cells in each layer were counted up to the same point. The cell counts of eosinophils, mast cells, and extraepithelial EC cells were expressed as the number of cells per cross-sectional area by multiplying the no. of cells per $\mathrm{mm}^{2}$ by the cross-sectional area of each layer. Number of cells per $\mathrm{mm}^{2}$ was obtained using the field area of the high power objective (Labomed CXL binocular microscope; field area: $0.195 \mathrm{~mm}^{2}$ ).

Number of epithelial EC cells per crypt in each case was obtained by counting the total number of EC cells in all crypts $(x)$ and the number of crypts $(y)$.

Number of EC cells per crypt $=$ Total number of EC cells in all crypts $(x)$ /Number of crypts $(y)$.

\section{Results}

Cases of acute appendicitis were characterized by neutrophil infiltration of the muscle layer. All cases contained significant number of eosinophils within the muscle. These cells were often seen along with edema and muscle fiber separation (-Fig. 1A).

Epithelial and extraepithelial EC cells stained for chromogranin are shown in - Fig. 1B-D.

Nondegranulated mast cells characterized by metachromasia with Toluidine blue in lamina propria as well as submucosa and muscle layer are shown in - Figs. $2 \mathbf{A}$ and $\mathbf{B}$. The total mast cells as represented by staining for CD-117 are seen in - Figs. 2C and D. CD-117 also stains the interstitial cells of Cajal within the muscle layer. These are thin, long, and fiber like and can be easily distinguished from the mast cells ( - Fig. 2D).

The counts of various cells per unit area in normal appendix and cases of acute appendicitis are shown in - Table $\mathbf{1}$. - Table 2 shows the comparison of total cross-sectional areas between acute appendicitis and normal appendix. The cell counts per cross-sectional area of lamina propria, submucosa, and muscle layer in normal appendix and acute appendicitis can be seen in - Table 3 . 


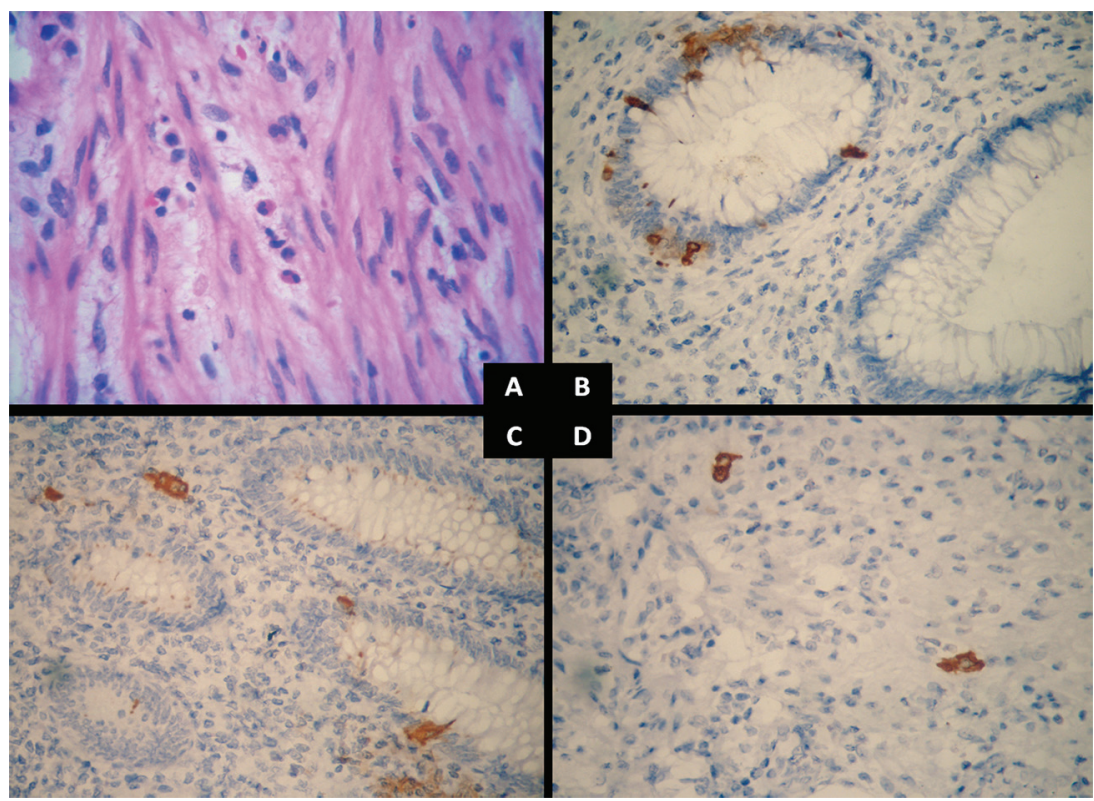

Fig. 1 (A) Neutrophils and eosinophils infiltrating muscle in a case of acute appendicitis. Note the edema separating muscle fibers in areas of eosinophil infiltration. H\&E $\times$ 400. H\&E, Hematoxylin and Eosin.(B) Enterochromaffin cells in the crypts of appendix. Immunohistochemistry for Chromogranin $\times 400$. (C) Enterochromaffin cells in crypts and outside the crypts in the lamina propria. Immunohistochemistry for Chromogranin $\times 400$. (D) Extraepithelial enterochromaffin cells in the lamina propria. Immunohistochemistry for chromogranin $\times 400$.

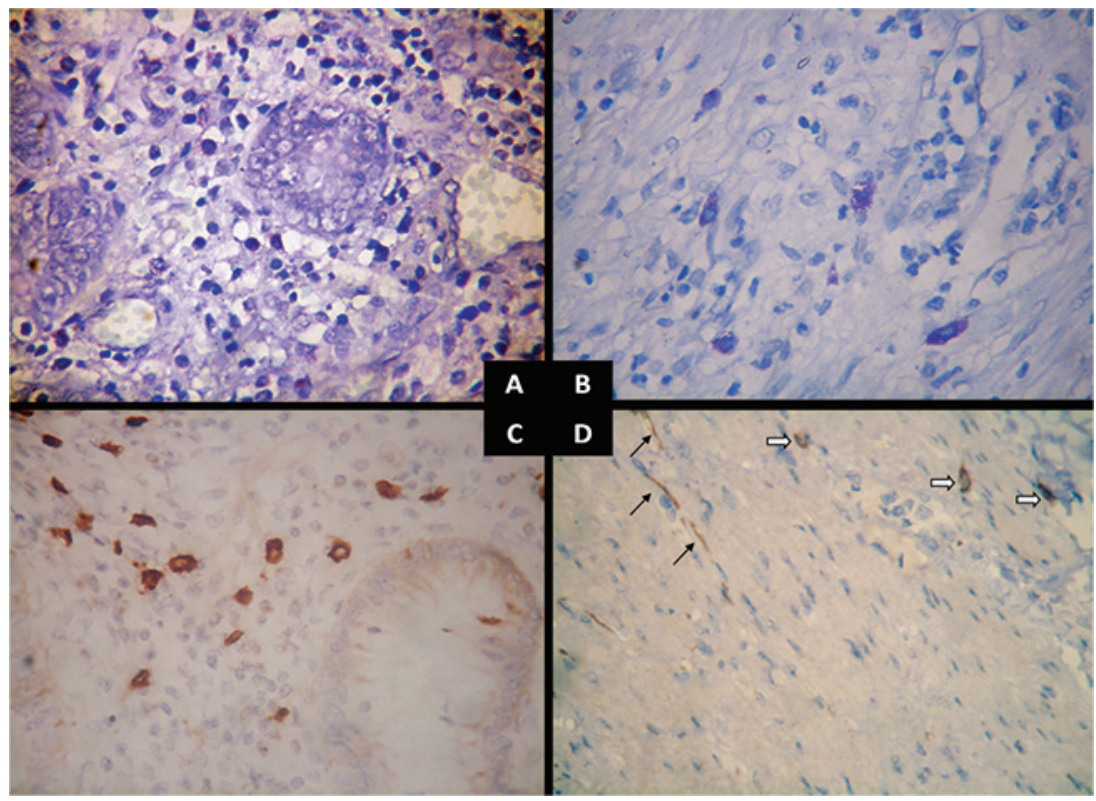

Fig. 2 (A) Mast cells in the lamina propria. Toluidine blue $\times 400$. (B) Mast cells in the submucosa and muscle layer. Toluidine blue $\times 400$. (C) Mast cells in the lamina propria. Immunohistochemistry for CD-117 $\times 400$. (D) Mast cells in the muscle layer (white arrows). This can be differentiated from the thin linear interstitial cells of Cajal (black arrows. Immunohistochemistry for CD-117 × 400).

\section{Discussion}

Higher serotonin levels in the blood and increased excretion of 5-Hydroxy indoleacetic acid (5-HIAA) in the urine of patients with acute appendicitis seem to be well documented. ${ }^{5-8}$ Most of these papers assume that the increase of serotonin or its metabolites is due to the degranulation of EC cells found in the appendix.

There is only one study that links the source of raised blood serotonin to EC cells and subepithelial neuroendocrine cells (SNC) within the lamina propria. ${ }^{9}$ The data from our study do not support these findings. We used chromogranin immunostaining to delineate the neuroendocrine cells in the appendix. The number of EC cells per crypt as well as the SNC counts did not show any statistically significant difference between acute appendicitis and normal appendices (-Table 1).

The disparity between the two studies could be due to the differences in the way sections are taken from the appendix. We took sections of acute appendicitis in which the epithelium was intact and the lamina propria showed negligible inflammation for the chromogranin staining. Sections from 
Table 1 Cell and fiber counts per unit area in acute appendicitis and normal appendix

\begin{tabular}{|c|c|c|c|}
\hline \multirow[t]{2}{*}{ Type of cell/fiber } & \multicolumn{2}{|c|}{ Mean $(95 \% \mathrm{Cl})$} & \multirow[t]{2}{*}{$p$-Values } \\
\hline & Acute appendicitis & Normal appendix & \\
\hline \multicolumn{4}{|l|}{ Enterochromaffin cells (EC) } \\
\hline EC cells/crypt & $0.37(0.25-0.50)$ & $0.50(0.27-0.73)$ & 0.27 \\
\hline Extraepithelial EC cells/mm² & $3.14(0.98-5.30)$ & $3.30(0.45-6.15)$ & 0.92 \\
\hline \multicolumn{4}{|l|}{ Eosinophils } \\
\hline Eosinophils in muscle layer $/ \mathrm{mm}^{2}$ & $72.9(33.8-112.0)$ & $2.1(0.4-4.7)$ & 0.005 \\
\hline \multicolumn{4}{|l|}{ Mast cells } \\
\hline Toluidine blue stained mast cells in lamina propria $/ \mathrm{mm}^{2}$ & $15.6(9.1-22.2)$ & $28.9(12.8-45.1)$ & 0.07 \\
\hline CD117 stained mast cells in lamina propria $/ \mathrm{mm}^{2}$ & $220.8(173.5-268.1)$ & $214.6(169.8-59.4)$ & 0.85 \\
\hline Toluidine blue stained mast cells in submucosa $/ \mathrm{mm}^{2}$ & $46.6(33.6-59.6)$ & $59.2(33.3-85.2)$ & 0.30 \\
\hline CD117 stained mast cells in submucosa $/ \mathrm{mm}^{2}$ & $140.6(93.6-187.5)$ & $141.1(88.8-193.4)$ & 0.99 \\
\hline Toluidine blue stained mast cells in muscle layer $/ \mathrm{mm}^{2}$ & $90.7(56.2-125.2)$ & $85.4(952.3-118.4)$ & 0.82 \\
\hline CD117 stained mast cells in muscle layer $/ \mathrm{mm}^{2}$ & $233.3(132.1-334.5)$ & $278.7(87.1-470.3)$ & 0.62 \\
\hline Estimate of degranulated mast cells in submucosa $/ \mathrm{mm}^{2}$ & $103.9(61.2-146.5)$ & $73.7(11.8-135.6)$ & 0.36 \\
\hline Estimate of degranulated mast cells in muscle layer $/ \mathrm{mm}^{2}$ & $139.7(40.9-238.5)$ & $193.4(2.5-389.3)$ & 0.56 \\
\hline
\end{tabular}

Abbreviation: $\mathrm{Cl}$, confidence interval.

Note: Values in bold are statistically significant.

Table 2 Comparison of cross-sectional areas in acute appendicitis and normal appendix

\begin{tabular}{|l|l|l|l|}
\hline \multirow{2}{*}{ Layer } & \multicolumn{2}{|c|}{ Mean (95\% CI) } & \multirow{2}{*}{$p$-Values } \\
\cline { 2 - 4 } & Acute appendicitis & Normal appendix & \\
\hline Lamina propria & $11.5(8.3-14.6)$ & $11.15(7.3-15.1)$ & 0.893 \\
\hline Submucosa & $13.6(9.1-18.1)$ & $4.7(2.5-6.8)$ & 0.003 \\
\hline Muscle layer & $18.2(13.2-23.1)$ & $7.1(4.0-10.2)$ & 0.001 \\
\hline
\end{tabular}

Abbreviation: $\mathrm{Cl}$, confidence interval.

Table 3 Cell and fiber counts per whole cross-sectional area of lamina propria, submucosa, and muscle layers in acute appendicitis and normal appendix

\begin{tabular}{|c|c|c|c|}
\hline \multirow[t]{2}{*}{ Type of cell/fiber } & \multicolumn{2}{|c|}{ Mean $(95 \% \mathrm{Cl})$} & \multirow[t]{2}{*}{ p-Values } \\
\hline & Acute appendicitis & Normal appendix & \\
\hline \multicolumn{4}{|l|}{ Enterochromaffin cells (EC) } \\
\hline Extraepithelial EC cells & $36.03(14.6057 .46)$ & $33.76(8.7258 .80)$ & 0.88 \\
\hline \multicolumn{4}{|l|}{ Eosinophils } \\
\hline Eosinophils in muscle layer & $1,450.7(464.2-2,437.2)$ & $13.6(3.931 .0)$ & 0.02 \\
\hline \multicolumn{4}{|l|}{ Mast cells } \\
\hline Toluidine blue stained mast cells in lamina propria & $182.2(90.3274 .1)$ & 315.1 (99.4 530.7) & 0.17 \\
\hline CD117 stained mast cells in lamina propria & $2,518.8(1,539.53,498.0)$ & 2,478.6 (1,299.5 3,657.7) & 0.95 \\
\hline Toluidine blue stained mast cells in submucosa & $636.0(343.7928 .3)$ & $315.3(84.2546 .5)$ & 0.09 \\
\hline CD117 stained mast cells in submucosa & $1,687.4(1,010.72,364.2)$ & $664.1(354.3974 .0)$ & 0.02 \\
\hline Toluidine blue stained mast cells in muscle layer & 1,480.1 (955.7 2,004.6) & $650.8(312.9988 .7)$ & 0.02 \\
\hline CD117 stained mast cells in muscle layer & $3,621.2(2,628.04,614.4)$ & $1,743.9(533.02,954.9)$ & 0.01 \\
\hline Estimate of degranulated mast cells in submucosa & $1,136.4(641.61,631.2)$ & $285.3(28.0598 .6)$ & 0.01 \\
\hline $\begin{array}{l}\text { Estimate of degranulated mast cells in muscle } \\
\text { layer }\end{array}$ & $2,090.4(1,106.93,073.8)$ & $1,093.1(75.32,261.5)$ & 0.16 \\
\hline
\end{tabular}

Abbreviation: $\mathrm{Cl}$, confidence interval.

Note: Values in bold are statistically significant. 
the tip (rich in EC cells) were avoided in both the groups. Details regarding the sections are not provided in the study by Vasei et al. ${ }^{9}$ It is possible that in sections with significant inflammation of lamina propria degranulation or loss of neuroendocrine cells may be a secondary phenomenon. Similarly, if there are proportionately more sections from the tip area among the control groups, EC cell counts may be overestimated in the controls compared with the cases. Significantly, unlike Vasei et al, we found no case of acute appendicitis in which EC cells were absent in the crypts or outside.

If $\mathrm{EC}$ cells were not the main source of increased serotonin in acute appendicitis, what could be the alternative? It is now known that human mast cells are capable of serotonin synthesis and release..$^{10}$ The proposition that mast cells could be a source of increased serotonin in acute appendicitis becomes attractive in the light of the allergic theory proposed for the disease. ${ }^{3}$ Indeed, the increase of eosinophils in acute appendicitis which led to the theory has been confirmed by others and once again in this study. ${ }^{11,12}$ Serotonin itself can be chemotactic to eosinophils. ${ }^{13}$ However, studies comparing mast cell numbers in acute appendicitis and normal appendices have yielded conflicting results. Naik et al found mast cell numbers to be decreased in acute appendicitis when compared with normal while Singh et al and Mysorekar et al found it to be increased in acute appendicitis. ${ }^{11,12,14}$ Mast cells were demonstrated by Toluidine blue in these studies. ${ }^{11,12}$ Aravindan found no significant difference in mast cells demonstrated by Giemsa stain in the muscle layer, between appendicitis and normal. ${ }^{3}$ Coşkun et al found increased mast cell numbers in acute appendicitis by immunohistochemical staining for mast cell tryptase. ${ }^{15}$

Toluidine blue, Giemsa, or mast cell tryptase stains the mast cell granules. The intact mast cells are well stained by these methods. However, the degranulated ones are either poorly stained or not stained at all. Moreover, metachromatic staining by Toluidine blue or Giemsa may be poor or absent in many mucosal mast cells. It is thus understandable that counts obtained by these methods do not reflect the total mast cell numbers and the extent of degranulation.

In this study, we employed a different strategy to estimate the extent of mast cell degranulation. CD-117 (c-kit receptor) is strongly expressed on the mast cell membrane and is not affected by the state of degranulation. We reasoned that by subtracting mast cell counts obtained by Toluidine blue staining from that obtained by CD-117 staining, we would be able to arrive at a reasonable estimate of the extent of mast cell degranulation. Though this would work well with connective tissue type mast cells in the submucosa and the muscle layer, it may not be satisfactory for mucosal mast cells for reasons mentioned above. An additional problem is that CD-117 also stains the interstitial cells of Cajal in the muscle layer. But these have a distinct appearance and can easily be distinguished from the mast cells ( - Fig. 2D).

- Table 1 shows the mast cell counts obtained by the two methods and the estimate of degranulation in the submucosa and muscle in acute appendicitis and the normal appendix. Toluidine blue stained mast cells are lower in the mucosa in acute appendicitis when compared with the normal appendix, but this falls short of significance. There are no significant differences in the CD-117 and Toluidine blue counts and estimates of degranulation in the submucosa and muscle layer. But the counts expressed per unit area as in - Table 1 do not reflect the real state of affairs. In acute appendicitis, the organ is swollen and enlarged due to inflammatory edema. Consequently, the counts expressed per unit area may be underestimations in case of acute appendicitis.

The comparison of cross-sectional areas between acute appendicitis and the normal appendix is shown in - Table 2 . It can be seen that the cross-sectional area of submucosa and muscle layer together are roughly equal to that of lamina propria in normal appendices. On the other hand, submucosa and muscle layer together account for nearly double the area of lamina propria in acute appendicitis. This is due to the large amount of edema fluid accumulating in the submucosa and muscle. The area of lamina propria is not significantly different in normal appendix and appendicitis.

- Table 3 shows the comparison of mast cell counts between acute appendicitis and normal appendix per total cross-sectional area of lamina propria, submucosa, and the muscle layer. It is seen that degranulated mast cells are much more in the submucosa and muscle layer (significant in the first case) and that this is mainly the result of an increase in CD-117 stained mast cells in these layers.

Also seen from - Table 3 is the fact that extraepithelial EC cells are not significantly different in the cross-sectional areas of acute appendicitis and normal appendix. The possibility that the source of raised serotonin in acute appendicitis could be degranulated mast cells, possibly along with platelets thus becomes very strong. The mast cell degranulation can also account for the inflammatory edema and accumulation of edema even before appearance of neutrophils on the scene.

To conclude, degranulated mast cells rather than EC cells may be the source of raised serotonin in acute appendicitis. This is in conformance with the allergic theory of acute appendicitis.

\section{Funding}

None.

\section{Conflict of Interest}

None.

\section{Acknowledgment}

None.

\section{References}

1 Bosak Versic A, Glavan N, Bukvic N, Tomasic Z, Nikolic H. Does elevated urinary 5-hydroxyindole acetic acid level predict acute appendicitis in children? Emerg Med J 2016;33(12):848-852

2 Rørdam P, Mortensen P, Hindberg I, Christiansen J. Acute appendicitis and plasma concentration of serotonin. Acta Chir Scand 1987;153(7-8):437-439

3 Aravindan KP. Eosinophils in acute appendicitis: possible significance. Indian J Pathol Microbiol 1997;40(4):491-498

4 Santosh G, Aravindan KP. Evidence for eosinophil degranulation in acute appendicitis. Indian J Pathol Microbiol 2008;51(2):172-174 
5 Mentes O, Eryilmaz M, Harlak A, et al. The importance of urine 5-hydroxyindoleacetic acid levels in the early diagnosis of acute appendicitis. Am J Emerg Med 2009;27(4):409-412

6 Bolandparvaz S, Vasei M, Owji AA, et al. Urinary 5-hydroxy indole acetic acid as a test for early diagnosis of acute appendicitis. Clin Biochem 2004;37(11):985-989

7 Kalra U, Chitkara N, Dadoo RC, Singh GP, Gulati P, Narula S. Evaluation of plasma serotonin concentration in acute appendicitis. Indian J Gastroenterol 1997;16(1):18-19

8 Oruc MT, Kulah B, Ozozan O, et al. The value of 5-hydroxy indole acetic acid measurement in spot urine in diagnosis of acute appendicitis. East Afr Med J 2004;81(1):40-41

9 Vasei M, Zakeri Z, Azarpira N, Hosseini SV, Solaymani-Dodaran M. Serotonin content of normal and inflamed appendix: a possible role of serotonin in acute appendicitis. APMIS 2008;116(11):947-952

10 Kushnir-Sukhov NM, Brown JM, Wu Y, Kirshenbaum A, Metcalfe DD. Human mast cells are capable of serotonin synthesis and release. J Allergy Clin Immunol 2007;119(2): 498-499

11 Singh UR, Malhotra A, Bhatia A. Eosinophils, mast cells, nerves and ganglion cells in appendicitis. Indian J Surg 2008;70(5):231-234

12 Mysorekar VV, Chanda S, Dandeka CP. Mast cells in surgically resected appendices. Indian J Pathol Microbiol 2006;49(2): 229-233

13 Boehme SA, Lio FM, Sikora L, et al. Cutting edge: serotonin is a chemotactic factor for eosinophils and functions additively with eotaxin. J Immunol 2004;173(6):3599-3603

14 Naik R, Gowda RJ, Pai MR. Mast cell count in surgically resected appendices. J Indian Med Assoc 1997;95(11):571-572

15 Coşkun N, Indel SM, Elpek GO. Mast cell density and neuronal hypertrophy in patients with acute appendicitis. Turk J Gastroenterol 2003;14(1):54-58 